\title{
Development of Siliconized Epoxy Resins and Their Application as Anticorrosive Coatings
}

\author{
Prashant Gupta, Madhu Bajpai \\ Department of Oil \& Paint Technology, H. B. Technological Institute, Kanpur, India \\ E-mail:prashant123hbti@gmail.com,madhubajpai_6@rediffmail.com \\ Received March 31, 2011; revised May 17, 2011; accepted July 3, 2011
}

\begin{abstract}
The present work involves the development of siliconized epoxy resin to overcome the drawback of epoxy resin like poor impact strength, high rigidity and moisture absorbing nature because of which they are not applied as corrosion resistant coating. By embedding silicone into the back bone of polymeric resin the above drawback can be reduced to substantial level. For achieving this, siliconised epoxy resins were prepared by reacting amine terminated silicone resin with novolac epoxy resin and meta-phenylenediamine was used as curing agent. The applied films of coating were baked at $150^{\circ} \mathrm{C}$. Cured films were evaluated for their thermal, mechanical, chemical and corrosion resistance properties to ascertain the commercial utility of these eco-friendly resins for use in anti corrosive formulations. The siliconized epoxy resins system was found to exhibit good thermal and anticorrosive properties.
\end{abstract}

Keywords: Epoxy Resin, Silicone Resin, Anticorrosive Coatings

\section{Introduction}

A novel coating of high performance polymeric material is a need of today. These polymeric materials have superior mechanical, thermal and anticorrosive characteristics ideally suitable for adverse environmental conditions [1]. Inorganic-organic hybrid resins have become a creative polymer with unique combination of distinctive properties of both constituents for applications in various industries.

Epoxy resins are widely used in protective coatings, adhesives, sealant, fiber reinforced composites and electronic industry due to their outstanding surface properties like low shrinkage, ease of cure and possessing good moisture, solvent and chemical resistance, and excellent adhesion performances [2,3]. They lack fracture resistance, impact strength, low thermal stability, low pigment holding ability, flexibility and poor hydrophobicity, which restrict their wide application in the field of coatings and paints $[4,5]$. To improve these properties the component like rubber, polyurethane silicone are added as modifier to the epoxy resins [6-8].

Silicones are used in coating materials because of the following properties:

- improved water repellency

- improved thermal stability; resistance to oxidation

- they retain physical properties over a wide range of temperature

- low toxicity

- they impart unique flexibility to the backbone chain and intrinsic surface active property.

Silicone is suitable modifier for epoxy resins. The modified resin has superior thermal and thermo-oxidative stability, fracture energy, excellent moisture resistance, partial ionic nature, low surface energy and good hydrophobicity [9].

Aliphatic epoxy modified polysiloxane coatings can be prepared by the combination of aliphatic epoxy resins, polysiloxane, organo oxysilane and difunctional aminosilanes hardners which provide highly improved resistance to ultraviolet and weathering in sunlight and improved chemical and corrosion resistance.

In practical applications, amine-based hardeners hold the largest share in epoxy hardener markets. Aromatic amine cured epoxy resin systems have excellent resistance to water, solvents and alkaline solutions as well as a range of good to excellent dilute acid resistance [10,11].

Generally, the incorporation of siloxane into polymer has been carried out through physical blending methods $[12,13]$. The blending of siloxane and epoxy causes an increase in viscosity, phase separation and bleeding of siloxane component of the blended system.

In the present work an attempt has been made to im- 
prove the shortcomings of siloxane epoxy blended coating. The properties of novolac epoxy resin are enhanced by embedding the amine terminated silicone into the backbone of polymeric resin. As silicone is chemically bonded to epoxy resin, the resulting materials have desired properties and with more consistent results.

\section{Experimental}

\subsection{Materials}

Phenol novolac epoxy resin, Synthesized in laboratory, Epichlorohydrin, EMerck, Diethoxydimethyl silane, Aldrich $\gamma$-aminopropyl diethoxy methyl silane, Lancaster.

\subsection{Methods}

\subsubsection{Synthesis of Novolac Resin}

Novolac Resin was prepared by condensation reaction between phenol and formaldehyde in acidic medium. Initially, phenol (1 mole) with some quantity of water was taken in three neck flask. The $\mathrm{pH}$ was adjusted to 0.5 with sulphuric acid (used as catalyst) and the contents were heated to $90^{\circ} \mathrm{C}$ with constant stirring. The required amount ( 0.5 mole) of formaldehyde (37\% formaline solution) was added over a period of 3 hours through a dropping funnel, and stirring was continued for an additional 30 minutes, water was then removed under vacuum.

\subsubsection{Synthesis of Epoxy Novolac Resin}

Laboratory prepared Novolac Novolac Resin (1 mole) was reacted with Epichlorohydrin (10 mole) at $110^{\circ} \mathrm{C}$ and $40 \%$ Sodium hydroxide solution was added gradually to the reactants over a period of 3 hours through a dropping funnel. After completion of reaction, salt $(\mathrm{NaCl})$ was removed by washing with hot water and then water was removed through vacuum distillation.

\subsubsection{Determination of Epoxide Equivalent Weight (EEW)}

Epoxide equivalent weight was determined by standard BIS method.

\subsubsection{Cohydrolysis of Diethoxydimethyl Silane and $\gamma$-Aminopropyldiethoxy Methyl Silane}

Calculated amount of Diethoxydimethyl silane and $\gamma$ - aminopropyldiethoxy methyl silane in 97:3 ratio were taken in three-necked flask, $50 \mathrm{ml}$ aq. alchohol (50:50) was added dropwise. The reaction was continued at $0^{\circ} \mathrm{C}$ with constant stirring. After complete addition of aqueous alcohol, the reaction was further continued for half an hour. The mixture was separated and distilled to make it solvent free. The resin was dried.

\subsection{Characterization of Resins}

The characterization of synthesized resins like epoxide equivalent and texture appearance are shown in Table 1.

\subsection{Coating Composition and Film Preparation}

The coating compositions were prepared by incorporation of amino terminated silicone resin in the ratio of 1.5 to 7.5 with curing agent (conventional amine).

Simultaneously a standard was also prepared by reacting epoxy resin with conventional amine.

The samples EA, EAS $1, \mathrm{EAS}_{2}, \mathrm{EAS}_{3}, \mathrm{EAS}_{4}$ and $\mathrm{EAS}_{5}$ of different molar ratio (as shown in Table 2) were applied on steel and glass panels with the help of 100a film applicator. All efforts were made to maintain a uniform film thickness of $100 \mu$ for the general mechanical and chemical resistance properties. The films were cured at $150^{\circ} \mathrm{C}$ till becomes tack free.

\subsection{Curing of Epoxy Resin}

The curing of the above prepared resin was carried out by using different curing agent under varying conditions:

a) Curing of epoxy resin with aromatic amine: The epoxy resin was melted and mixed with stoichiometric amount of curing agent, i.e. m-phenylenediamine (MPDA) at a temperature $80^{\circ} \mathrm{C}$.

b) Curing of epoxy resin with mpda and amino terminated silicone resin in different ratios at $150^{\circ} \mathrm{C}$.

\section{Results and Discussion}

\subsection{Spectral Analysis}

Figure 1 shows the I.R. spectra of novolac epoxy resin. A prominent band is observed at $940 \mathrm{~cm}^{-1}$, which shows<smiles>[R10]Oc1cccc(Cc2ccccc2O)c1O</smiles>

Synthesis of Novolac Resin 


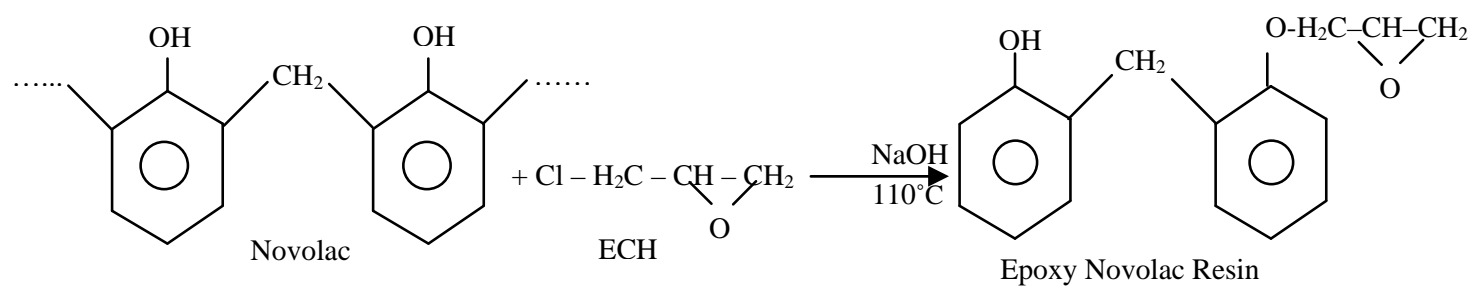

Synthesis of Novolac Epoxy Resin

\section{Reactions}

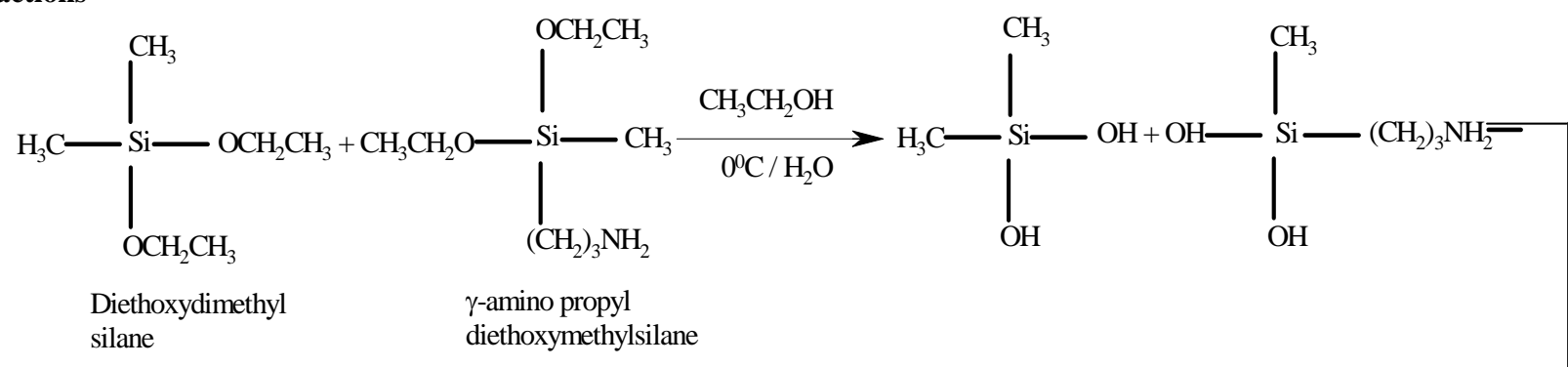<smiles>C[Si]1(C)O[Si](C)(C)O[Si](C)(CN)O[Si](C)(CN)O1</smiles>

Aminosiloxane

Cohydrolysis of diethoxydimethylsilane and $\gamma$-aminopropyldiethoxy methyl silane

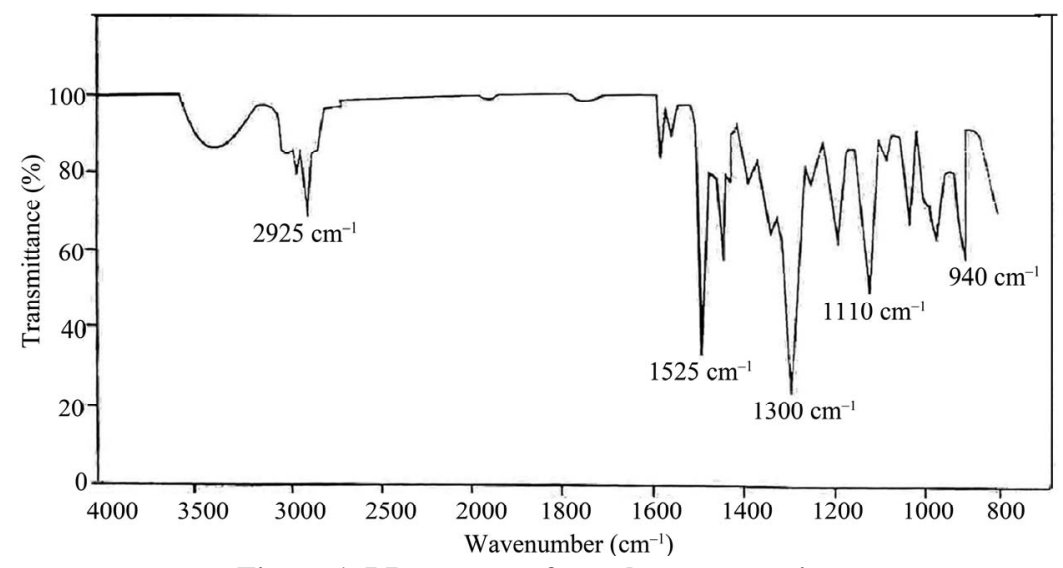

Figure 1. I.R. spectra of novolac epoxy resin.

the presence of oxirane ring in epoxy resin.

The formation of amino silicone resin was also con-

Table 1. Characteristics of epoxy and silicone resins.

\begin{tabular}{cll}
\hline S.No. & \multicolumn{1}{c}{ Sample } & \multicolumn{1}{c}{ Texture appearance } \\
\hline 1. & $\begin{array}{l}\text { Novolac based epoxy resin } \\
\text { (epoxide equivalent }=190)\end{array}$ & $\begin{array}{l}\text { Highly viscous, } \\
\text { water white in colour. }\end{array}$ \\
2. & Amino silicone resin & Viscous, pale yellow \\
\hline
\end{tabular}

Table 2. Formulation of coating samples.

\begin{tabular}{cccc}
\hline Sample & Epoxy resin & MPDA & $\begin{array}{c}\text { Amino terminated sili- } \\
\text { cone resin (w/w) }\end{array}$ \\
\hline EA & 100 & 15.0 & -- \\
EAS $_{1}$ & 100 & 13.5 & 1.5 \\
EAS $_{2}$ & 100 & 12.0 & 3.0 \\
EAS $_{3}$ & 100 & 10.5 & 4.5 \\
EAS $_{4}$ & 100 & 9.0 & 6.0 \\
EAS $_{5}$ & 100 & 7.5 & 7.5 \\
\hline
\end{tabular}


firmed by the I.R. spectral analysis. A peak was observed at $1021 \mathrm{~cm}^{-1}$ referred as Si-O-Si linkage and a peak near $3369 \mathrm{~cm}^{-1}$ showed the presence of $-\mathrm{NH}_{2}$ group. The spectrum is presented in Figure 2.

\subsection{Evaluation of Film Properties}

The cured films were evaluated for their optical, mechanical, chemical resistance and anticorrosive properties as per the standard test methods viz. gloss at $60^{\circ}$ (ASTM: D523-99), scratch hardness (ASTM: D 5178), pencil hardness (ASTM: D 3363-00), chemical resistance (ASTM:D 1308-87) and solvent resistance (ASTM:D 5402).

\subsection{Mechanical Properties}

The results of evaluation of various mechanical properties have been shown in Table 3 .

a) Scratch hardness:

It was determined by using an automatic scratch hardness tester (Sheen U.K.). The scratch hardness varies from 1700 - $2000 \mathrm{~g}$. It is clear from the data that as we increase the silicone percentage the scratch hardness of the film goes on increasing.

b) Pencil hardness:

It was measured by using pencil hardness tester (Sheen U.K.). The coating films showed that it varies from $3 \mathrm{H}-$ $5 \mathrm{H}$. Higher pencil hardness is due to higher silicone content.

c) Cross-hatch adhesion:

It was measured by using crosscut adhesion tester (Sheen U.K.). All the coating films demonstrated good cross-hatch adhesion.

d) Flexibility:

Flexibility was determined by using $1 / 4$ inch Mandrel Bend tester (Sheen U.K.). Films of all the coating compositions passed $1 / 4$ inch mandrel bend test. Based on this qualitative measurement, it can be said that all the films had reasonably good flexibility.

e) Gloss:

It was measured by using triglossometer (Sheen U.K.). On watching the films at $60^{\circ}$ angle, it was observed that all coating films had good gloss.

\subsection{Chemical Resistance}

The cured films of coating samples were tested for their chemical resistance. The codified results of the chemical resistance have been presented in Table 4 .

a) Acid resistance:

To examine the acid resistance, coated films were immersed in $1.0 \mathrm{~N}$ aqueous solution of sulfuric acid. Results showed that all the samples exhibit from good to very good resistance against acid. b) Alkali resistance:

To examine the alkali resistance, coated films were immersed in $1.0 \mathrm{~N}$ aqueous solution of sodium hydroxide. These films showed good to excellent resistance against alkali. It was observed that sample with higher ratio of silicone were found to be excellent.

c) Water resistance:

All the coated films exhibited very good to excellent resistance against distilled water when they were exposed to it.

d) Solvents resistance:

All the coated films exhibited very good to excellent solvent resistance when they were exposed to non polar solvents like xylene and mineral turpentine oil. Resistance against MEK was fair to good because MEK is very polar solvent. Samples with high silicone content showed better performance than those having low content of silicone.

\subsection{Salt-Spray Test Results}

No visible corrosion products were seen on the surface of the unscratched area of the coated panels at the end of the salt-spray test. Corrosion products were seen mainly on scratched area of the coated panels. Corrosion is lower in the case of siliconized epoxy coated panels than in epoxy. Siliconized epoxy coated panels show excellent corrosion resistance in salt-spray test. The superior corrosion resistance showed by coating systems may be due to the inherent water repelling nature of silicone.

\subsection{TGA Analysis}

Figure 3 shows the TGA graph of the samples. Activation energy (E) for the thermal decomposition of siliconized epoxy has been evaluated from the dynamic thermograms. The fractional decomposition for the respective temperature has been evaluated from TGA graph. Higher value of activation energy (see Table 5) may be due to the presence of silicon in the resin. High activation energy for the decomposition of system leads to better thermal stability of the compound $[14,15]$.

\section{Conclusions}

Amino containing siliconised epoxy resin was synthe sized. The spectral analysis, thermal stability, mechanical and chemical resistance properties of siliconised epoxy resins were studied using FTIR, TGA and standard methods respectively. It was found that on increasing the ratio of silicone resin, the thermal stability was increased and the effect of amino silicone resin on epoxy resin im- 


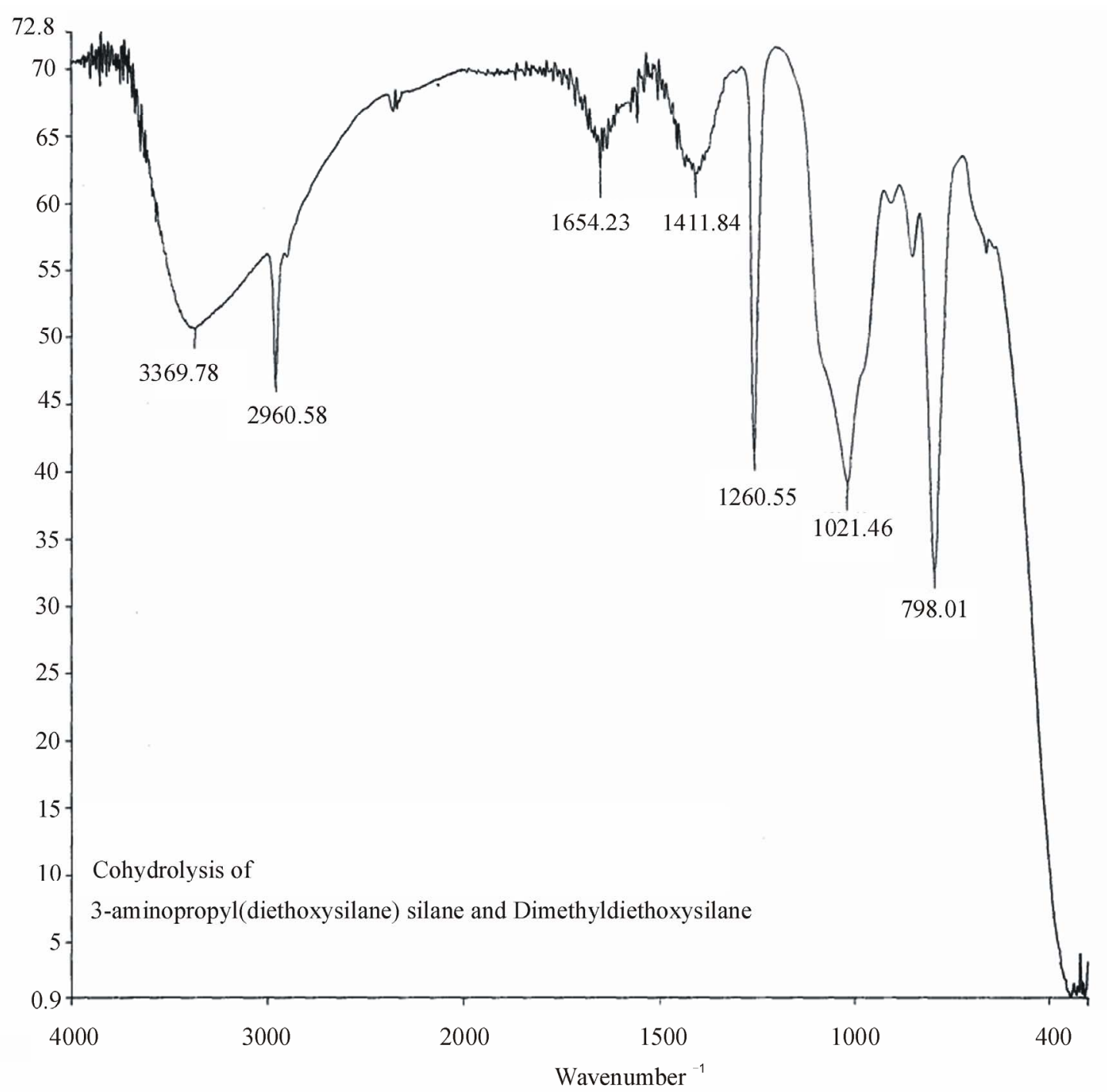

Figure 2. I.R. spectra of aminosilicone resin.

Table 3. Mechanical properties of cured films.

\begin{tabular}{|c|c|c|c|c|c|c|c|}
\hline \multirow{2}{*}{ S.No. } & \multirow{2}{*}{ Property } & \multicolumn{6}{|c|}{ Results } \\
\hline & & EA & $\mathrm{EAS}_{1}$ & $\mathrm{EAS}_{2}$ & $\mathrm{EAS}_{3}$ & $\mathrm{EAS}_{4}$ & $\mathrm{EAS}_{5}$ \\
\hline 1. & Scratch hardness (g) & 1700 & 1750 & 1800 & 1850 & 1900 & 2000 \\
\hline 2. & Pencil hardness & $3 \mathrm{H}$ & $3 \mathrm{H}$ & $4 \mathrm{H}$ & $4 \mathrm{H}$ & $4 \mathrm{H}$ & $5 \mathrm{H}$ \\
\hline 3. & Cross-hatch adhesion (\%) & 100 & 100 & 100 & 100 & 100 & 100 \\
\hline 4. & Flexibility (1/4” Mandrel) & pass & pass & pass & pass & pass & Pass \\
\hline 5. & Gloss at $60^{\circ}(\%)$ & 85 & 90 & $92-95$ & $92-97$ & $92-97$ & $95-99$ \\
\hline
\end{tabular}

Table 4. Chemical resistance of cured films.

\begin{tabular}{cccccccc}
\hline \multirow{2}{*}{ S.No. } & \multirow{2}{*}{ Property } & \multicolumn{6}{c}{ Results } \\
\cline { 3 - 7 } & & $\mathrm{EA}$ & $\mathrm{EAS}_{1}$ & $\mathrm{EAS}_{2}$ & $\mathrm{EAS}_{3}$ & $\mathrm{EAS}_{4}$ & $\mathrm{EAS}_{5}$ \\
\hline 1. & $1.0 \mathrm{~N} \mathrm{H}_{2} \mathrm{SO}_{4}$ & $\mathrm{G}$ & $\mathrm{G}$ & $\mathrm{G}$ & $\mathrm{VG}$ & $\mathrm{VG}$ & $\mathrm{VG}$ \\
2. & $1.0 \mathrm{~N} \mathrm{NaOH}$ & $\mathrm{G}$ & $\mathrm{G}$ & $\mathrm{VG}$ & $\mathrm{VG}$ & $\mathrm{VG}$ & $\mathrm{E}$ \\
3. & Distilled water & $\mathrm{VG}$ & $\mathrm{VG}$ & $\mathrm{E}$ & $\mathrm{E}$ & $\mathrm{E}$ & $\mathrm{E}$ \\
4. & Mineral turpentine oil & $\mathrm{VG}$ & $\mathrm{VG}$ & $\mathrm{VG}$ & $\mathrm{E}$ & $\mathrm{E}$ & $\mathrm{E}$ \\
5. & Methyl ethyl ketone & $\mathrm{F}$ & $\mathrm{F}$ & $\mathrm{F}$ & $\mathrm{F}$ & $\mathrm{G}$ & $\mathrm{G}$ \\
6. & Xylene & $\mathrm{VG}$ & $\mathrm{VG}$ & $\mathrm{VG}$ & $\mathrm{E}$ & $\mathrm{E}$ & $\mathrm{E}$ \\
\hline
\end{tabular}

P: poor; F: fair; G: good; VG: very good; E: excellent. 


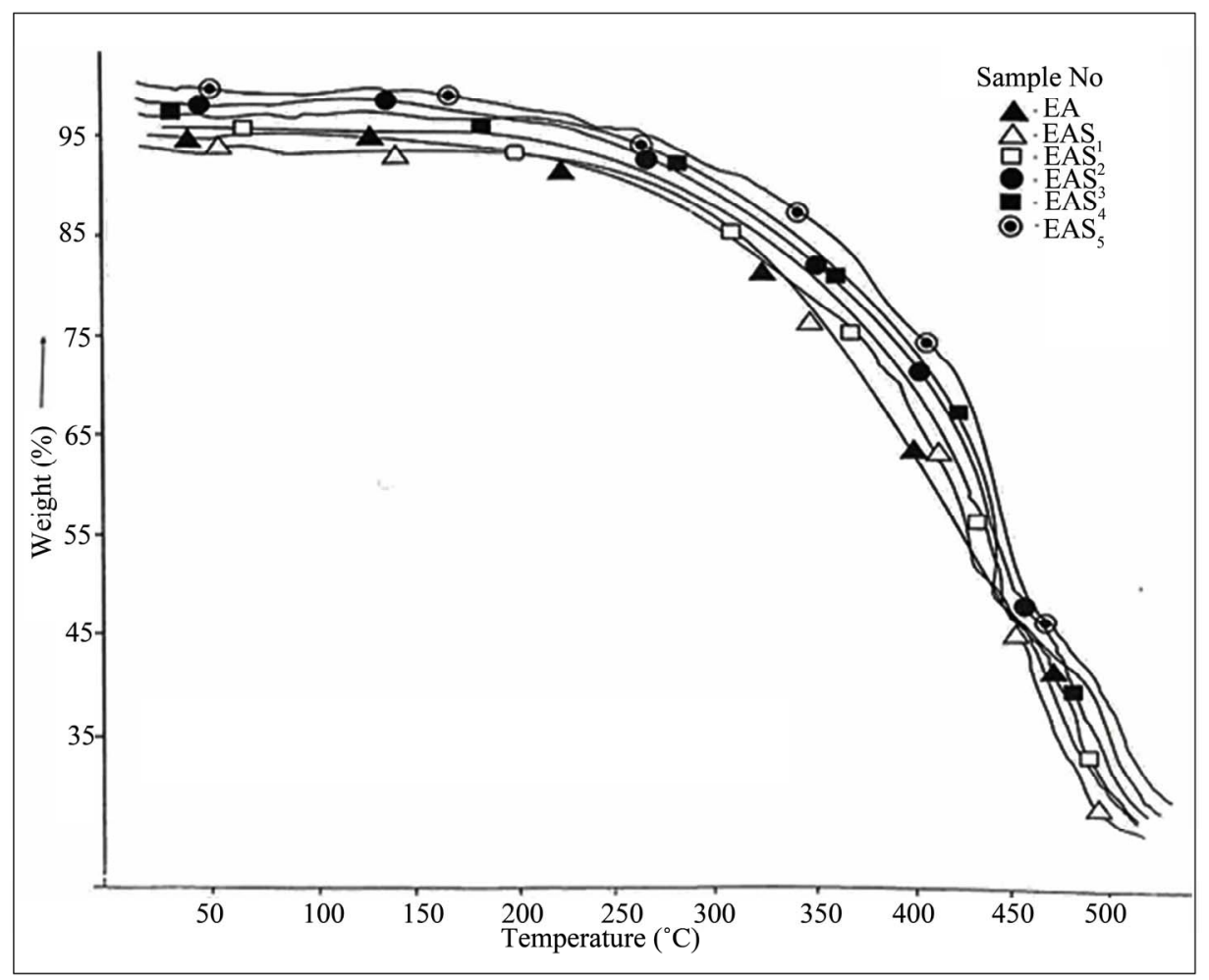

Figure 3. TGA graph.

Table 5. Activation energy of samples.

\begin{tabular}{ccc}
\hline S.No. & Sample & Activation energy (j/mole) \\
\hline 1 & EA & 18.2 \\
2 & EAS $_{1}$ & 20.1 \\
3 & EAS $_{2}$ & 22.3 \\
4 & EAS $_{3}$ & 22.5 \\
5 & EAS $_{4}$ & 23.1 \\
6 & EAS $_{5}$ & 24.2 \\
\hline
\end{tabular}

proved anticorrosive properties.

\section{References}

[1] S. A. Kumar and T. S. N. S. Narayana, "Thermal Properties of Siliconized Epoxy Interpenetrating Coatings," Progress in Organic Coatings, Vol. 45, No. 4, 2002, pp. 323330. doi:10.1016/S0300-9440(02)00062-0

[2] P. Khurana, S. Aggarwal, A. K. Narula and V. Choudhary, "Studies on Curing and Thermal Behaviour of DGEBA in the Presence of Bis(4-carboxyphenyl)dimethyl Silane," Polymer International, Vol. 52, No. 6, 2003, pp. 908-917. doi:10.1002/pi.1128

[3] H. Ren, J. Z. Sun, B. J. Wu and Q. Y. Zhan, "Synthesis and Curing Properties of Novel Novolac Curing Agent Containing Naphthyl and Dicyclopentadiene Moieties," Chinese Journal of Chemical Engineerin, Vol. 15, No. 1, 2007, pp. 127-131. doi:10.1016/S1004-9541(07)60045-7

[4] T. H. Ho and C. S. Wang, "Modification of Epoxy Resins with Polysiloxane Thermoplastic Polyurethane for Elec- tronic Encapsulation:1,” Polymer, Vol. 37, No. 13, 1996, pp. 2733-2742.

[5] S. T. Lin and S. K. Hang, "Thermal Degradation Study of Siloxane-DGEBA Epoxy Copolymers,” European Polymer Journal, Vol. 33, No. 3, 1997, pp. 365-373. doi:10.1016/S0014-3057(96)00175-9

[6] P. H. Sung and C. Y. Lin, "Polysiloxane-Modified Epoxy Polymer Networks-I Graft Interpenetrating Polymeric Networks,” European Polymer Journal, Vol. 33, No. 6, 1997, pp. 903-906. doi:10.1016/S0014-3057(96)00214-5

[7] S. Bhuniya and B. Adhikari, “Toughening of Epoxy Resin by Hydroxy Terminated Silicon Modified Polyurethane Oligomers,” Journal of Applied Polymer Science, Vol. 90, No. 6, 2003, pp. 1497-1506. doi:10.1002/app.12666

[8] U. Lauter, S. W. Kantor, K. Schmidt-Rohr and W. J. Macknight, "Vinyl Substituted Silphenylene Siloxane Copolymer: Noval High Temperature Elastomers" Macromolecules, Vol.32, No. 10, 1999, pp. 3426-3431. doi:10.1021/ma981292f

[9] J. Chojnowski, M. Cypryk, W. Scibioek and K. RozgaWijas, "Synthesis of Branched Polysiloxanes with Controlled Branching and Functionalization by Anionic Ring-Opening Polymerization,” Macromolecules, Vol. 36, No. 11, 2003, pp. 3890-3897. doi:10.1021/ma025920b

[10] S. Lu, W. Chun, J. Yu and X. Yang, "Preparation and Characterization of the Mesoporous $\mathrm{SiO}_{2}-\mathrm{TiO}_{2} /$ Epoxy Resin Hybrid Materials," Journal of Applied Polymer Science, Vol. 109, No. 4, 2008, pp. 2095-2102. 
doi:10.1002/app.27856

[11] P. F. Brunis, "Epoxy Resin Technology,” New York Interscience Publishers, New York, 1968.

[12] S. Ahmad, S. M. Ashraf and A. Hsanat, "Studies on Corrosion Protective Epoxidised Oil Modified DGEBA Epoxy Paint,” Paint India, Vol. 52, No. 1, 2002, pp. 47-51.

[13] S. Ahmad, S. M. Ashraf, S. N. Nusrat and A. Nsanat, "Synthesis, Characterization and Performance Evaluation of Hard, Anticorrosive Coatings Materials Derived from
Diglycidyl Ether of Bisphenol a Acrylates and Methacrylates," Journal of Applied Polymer Science, Vol. 95, No. 3, 2005, pp. 494-501. doi:10.1002/app.21202

[14] W. G. Potter, "Uses of Epoxy Resin,” Newnes-Butterworths, London, 1975.

[15] A. F. Yee and R. A. Pearson "Toughening Mechanism in Elastomer-Modified Epoxies Part-1 Mechanical Studies,” Journal of Material Science, Vol. 21, No. 7, 1986, pp. 2462-2474. 